\title{
Induction of Cell Proliferation and Cell Death in Human Follicle Dermal Papilla Cells by Zinc Chloride
}

\author{
F. M. TSAI, L. K. WANG ${ }^{1}$, M. L. CHEN, M. C. LEE, Y. Y. LIN AND C. H. WANG ${ }^{2,3 *}$ \\ Department of Research, Taipei Tzuchi Hospital, The Buddhist Tzuchi Medical Foundation, New Taipei City 231, ${ }^{1}$ Radiation \\ Biology Core Laboratory, Institute for Radiological Research, Chang Gung University/Chang Gung Memorial Hospital, Linkou, \\ Taoyuan 333, ${ }^{2}$ Department of Dermatology, Taipei Tzuchi Hospital, The Buddhist Tzuchi Medical Foundation, New Taipei City \\ 231, ${ }^{3}$ School of Medicine, Tzu Chi University, Hualien 970, Taiwan
}

\section{Tsai et al.: Zinc Induces Cell Proliferation and Cell Death in HFDPCs}

In the present investigation, the effects of zinc on the growth of human follicle dermal papilla cells were determined. A higher dose of zinc was found to significantly increase the proliferation of human follicle dermal papilla cells and the expression levels of cell cycle regulatory proteins. However, cell death, an increase in the apoptotic protein Bax, and caspase-3 activation were also observed in zinc-treated human follicle dermal papilla cells. The results from our present study suggest that the regulation of human follicle dermal papilla cells proliferation or death by zinc might be directly involved in hair regrowth in a narrow dose range.

Key words: Zinc, dermal papilla cells, cell cycle, cell death, caspase

Zinc is a mineral required by the body to support immune functions, protein synthesis, and hormone actions. It also supports more than 300 enzymatic functions, including carbonic anhydrase and carboxypeptidase, and serves a structural role in zinc finger transcription factors ${ }^{[1]}$. Most of the world's population is deficient in zinc, but profound zinc deficiency in humans is quite rare. Because zinc is required for immune functions, zinc-deficient persons experience an increased susceptibility to a broad range of pathogens ${ }^{[2]}$. Additionally, zinc deficiency may prevent the body from regulating hormones, such as thyroid hormone $\mathrm{e}^{[3]}$ and testosterone $\mathrm{e}^{[4]}$.

In addition to the regulation of immune functions and hormones, many studies have investigated the potential link between zinc deficiency and hair loss ${ }^{[5-8]}$. The effects of zinc on the regulation of hair regrowth are not well established, although the negative effects of zinc deficiency on hair growth are clear. Human follicle dermal papilla cells (HFDPCs) are specialized fibroblasts expressed at the base of hair follicles that are crucial for the induction of hair follicle growth. In this study, the effects of zinc were examined on cell growth and the death of HFDPCs and determined the underlying mechanism.

HFDPCs were purchased from PromoCell (Heidelberg, Germany). The cells were maintained in follicle dermal papilla cell basal medium (PromoCell) supplemented with $4 \%$ fetal calf serum, $0.4 \%$ bovine pituitary extract, $1 \mathrm{ng} / \mathrm{ml}$ basic fibroblast growth factor, and $5 \mu \mathrm{g} / \mathrm{ml}$ recombinant human insulin (PromoCell) at $37^{\circ}$ in $5 \% \mathrm{CO}_{2}$.

This is an open access article distributed under the terms of the Creative Commons Attribution-NonCommercial-ShareAlike 3.0 License, which allows others to remix, tweak, and build upon the work non-commercially, as long as the author is credited and the new creations are licensed under the identical terms

Accepted 12 May 2019

Revised 06 January 2019

Received 04 October 2018

Indian J Pharm Sci 2019;81(4):781-785 
The $4^{\text {th }}$ through the $10^{\text {th }}$ HFDPC population doublings were seeded at $1 \times 10^{4}$ cells/well in triplicate in 24-well plates. HFDPCs were then cultured in serumfree basal medium with various concentrations of $\mathrm{ZnCl}_{2}$ (Sigma-Aldrich, St. Louis, USA) for 24-48 h. A WST-1 assay and the release of lactate dehydrogenase (LDH) were used to analyze cell viability and cell death, respectively. Briefly, $100 \mu \mathrm{l}$ of WST-1 reagent (Roche Diagnostics, Mannheim, Germany) was added, and HFDPCs were further incubated at $37^{\circ}$ for $4 \mathrm{~h}$. Cells treated with WST-1 were then transferred to a 96-well plate, and the absorbance of each sample was measured at a wavelength of 450 and $650 \mathrm{~nm}$. The percentage of cell viability relative to the vehicle-treated cells was defined as [(A450-A650) of the drug-treated cells/ (A450-A650) of the control cells] $\times 100$. Measurement of the release of LDH using a cytotoxicity detection kit (Roche Diagnostics) was used to evaluate cell death. The percent LDH release was defined as [(A450A650) of the drug-treated cells /(A450-A650) of the control cells] $\times 100$.

Cell proliferation was assessed with a bromodeoxyuridine (BrdU) incorporation kit from Roche Diagnostics. Briefly, the $4^{\text {th }}$ through the $10^{\text {th }}$ HFDPC population doublings were seeded at $1 \times 10^{4}$ cells/well in triplicate in 24-well plates. HFDPCs were then cultured in serum-free basal medium with various concentrations of $\mathrm{ZnCl}_{2}$ for 24-48 h. Next, $10 \mu \mathrm{M}$ BrdU labeling solution was added, and the mixture was incubated for $12 \mathrm{~h}$. After removing the BrdU labeling solution, the cells were fixed and denatured with FixDenat solution for $30 \mathrm{~min}$ at $25^{\circ}$. After the samples were fixed, they were incubated for $90 \mathrm{~min}$ at $25^{\circ}$ with a peroxidase-labeled antiBrdU antibody and then incubated with a tetramethyl-benzidine substrate. The color reaction was developed, and the optical densities of the samples were measured in a multifunctional microplate reader (Infinite F200, Tecon, Durham, NC, USA), where the absorbance measurements of each well at wavelengths of 370 and $492 \mathrm{~nm}$ were recorded.

The cells were lysed in radioimmunoprecipitation assay buffer (50 mM Tris ( $\mathrm{pH} 8.0), 150 \mathrm{mM} \mathrm{NaCl}$, $1 \%$ NP-40, $0.5 \%$ sodium deoxycholate, $0.1 \%$ SDS) containing a protease inhibitor cocktail (Roche Diagnostics, Germany) and phosphatase inhibitors. Proteins $(15-60 \mu \mathrm{g})$ were separated on $12 \%$ polyacrylamide gels and transferred to polyvinylidene fluoride membranes. After the membranes were blocked, they were incubated with anticyclin D1 (Cell Signaling Technology, Beverly, MA, USA), anticyclin
E1 (Cell Signaling Technology), anticyclin A (Cell Signaling Technology), anticdk2, anticdk4, andicdc2 (Cell Signaling Technology), antiBcl-2, antiBax (Santa Cruz Biotechnology), antipAKT, antiAKT, antip-p44/ p42 ERK, antip44/p42 ERK, anticaspase-3 (Cell Signaling Technology), or antiactin (Sigma-Aldrich) antibody at $4^{\circ}$ for $12 \mathrm{~h}$. They were then incubated with corresponding horseradish peroxidase-conjugated secondary antibodies (Calbiochem, Darmstadt, Germany) at room temperature for $1 \mathrm{~h}$. Specific protein bands were developed using an Amersham ECL (Amersham, Bucks, UK). Relative protein expression was quantified following normalization to the levels of actin protein.

Data are expressed as the mean $\pm \mathrm{SD}$ of at least three replicates. Statistical analysis was performed using one-way ANOVA with the Dunnett's post hoc test. A p-value $<0.05$ was considered statistically significant.

To examine the effect of zinc chloride on the viability of HFDPCs, HFDPCs were treated with various doses of zinc chloride for 24-48 h. A reduction of cell viability was observed when HFDPCs were treated with a high dose of zinc chloride (100-1000 nM; fig. 1A). Since zinc chloride can reduce the viability of HFDPCs, next examined whether $2+$ charged ions play an important role in zinc-mediated cell death. No significant change was observed in cell viability when HFDPCs treated with all doses of magnesium chloride (0-1000 nM) in this study, suggesting that $2+$ charged ions did not affect the viability of HFDPCs.

Then, the effects of zinc chloride on cell proliferation and cell death in HFDPCs were examined. The proliferative activity in HFDPCs treated with 100$1000 \mathrm{nM}$ zinc chloride was significantly enhanced, ranging from 20 to $175.6 \%$ compared with the control cells (fig. 1B). In addition to the induction of cell proliferation, zinc chloride significantly increased the cell death of HFDPCs by 2.2- to 5.8-fold (fig. 1C).

Since zinc chloride can induce cell proliferation of HPDPCs, the production of cell cycle regulatory proteins in zinc chloride-treated HFDPCs was determined. Increased cyclin D1, cyclin E1, and cyclin A expression were observed in HFDPCs treated with a higher dose of zinc chloride (200-500 nM; fig. 2). In addition, increases in cdk $4, \operatorname{cdk} 2$, and cdc2 in zinc chloride-treated HFDPCs (200-500 nM; fig. 2) was observed. However, the production of cell cycleassociated proteins decreased when cells were treated with $1000 \mathrm{nM}$ zinc chloride. These results suggest that 
A

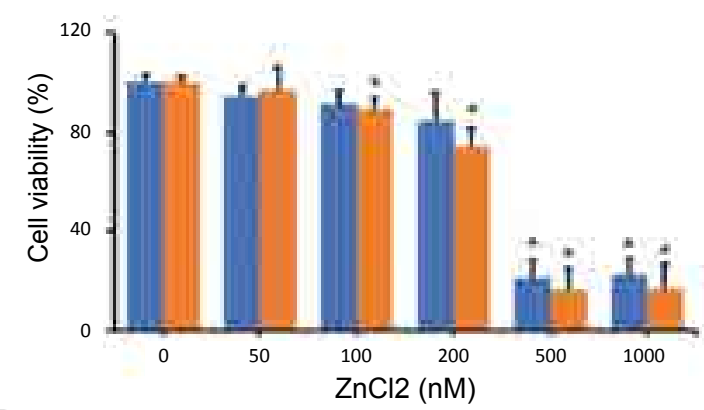

B

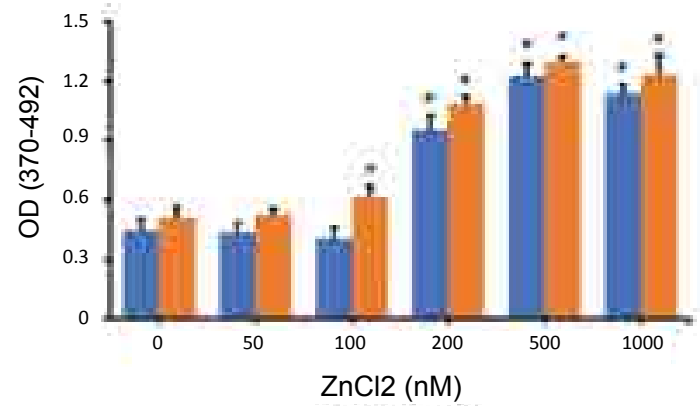

C

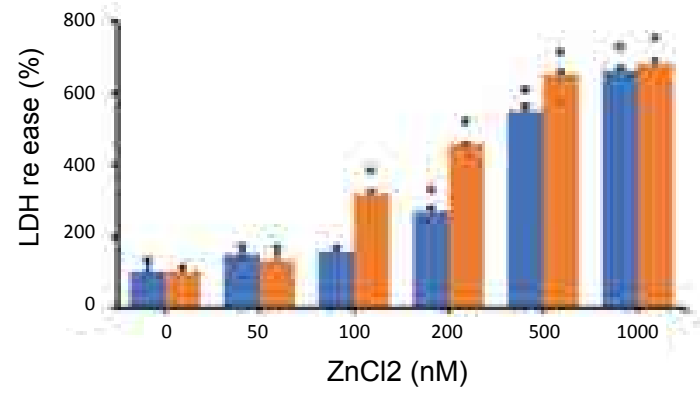

Fig. 1: Zinc chloride decreased HFDPC cell viability Cell viability (A), cell proliferation (B), and cell death (C) were measured by the WST-1, BrdU, and LDH assays, respectively. Representative results from three triplicate samples are shown, and the data are expressed as the means and standard deviations of the means after being normalized to the control group. $* \mathbf{P}<0.05$ when cells were treated with zinc chloride compared to cells that were treated with vehicle control; $\approx 24$ $h, \square 48 \mathrm{~h}$

zinc chloride at concentrations of 200-500 nM induces HFDPC proliferation by enhancing the progression of the cell cycle phases.

Activation of the epidermal growth factor receptor signaling pathway has been reported as necessary for the proliferation of papilla cells. The effects of zinc chloride were examined on the activation of AKT and ERK in HFDPCs. It was observed that a higher dose of zinc chloride (200-500 $\mathrm{nM}$ ) increased the expression of phosphorylated AKT and phosphorylated p44/p42 ERK in HFDPCs (fig. 3). In contrast, these increased levels of phosphorylated AKT and phosphorylated p44/p42 ERK decreased when HFDPCs were treated with $1000 \mathrm{nM}$ zinc chloride. No differences in the total expression levels of AKT or ERK were observed for cells treated with different doses of zinc chloride.

Since zinc chloride can induce cell death in HFDPCs, in this investigation the ability of zinc chloride to affect the levels of proteins associated with apoptosis (Bcl-2 and Bax) were examined. A dose-dependent decrease in antiapoptotic Bcl-2 production was observed in HFDPCs treated with zinc chloride (fig. 4). In contrast, the levels of apoptotic Bax expression increased when cells were treated with a high dose of ebastine (200$1000 \mathrm{nM})$. To identify the caspases associated with zinc chloride-induced cell death, the activation of effector caspase-3 was analysed. The cleaved (activated) form of caspase-3 fragments were detected in HFDPCs treated with a higher dose of zinc chloride (500$1000 \mathrm{nM}$ ). These observations indicate that zinc chloride can induce cell death of HFDPCs through caspase activation.

According to previous results, the plasma zinc level in the normal control is approximately $1.19 \mu \mathrm{M}^{[9]}$.

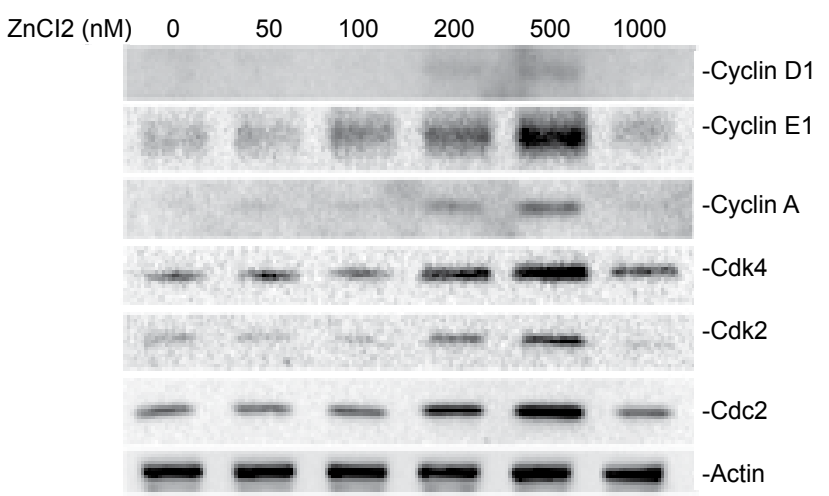

Fig. 2: Zinc chloride enhanced the expression of cell cycle regulatory proteins in HFDPCs

HFDPCs were supplied with fresh medium without serum and treated with the indicated concentrations of zinc chloride for 24 h. Cell lysates were prepared, and the levels of cyclin D1, cyclin E1, cyclin A, Cdk4, Cdk2, Cdc2, and actin were determined by immunoblotting

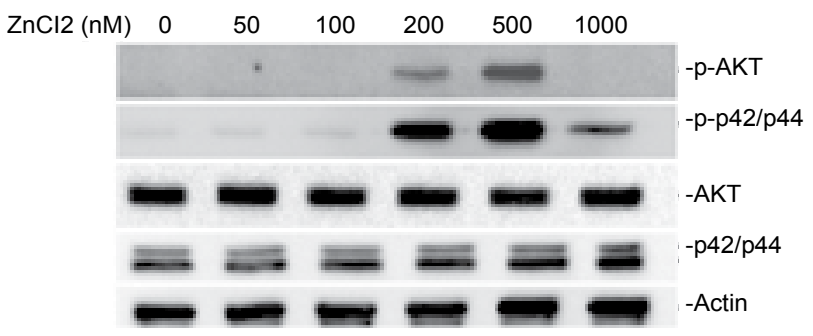

Fig. 3: Zinc chloride increased p-AKT and p-p44/p42 ERK in HFDPCs

Cell lysates from HFDPCs were prepared, and the levels of p-AKT, total AKT, p- p44/p42 ERK, total p44/42 ERK, and actin were determined by immunoblotting 


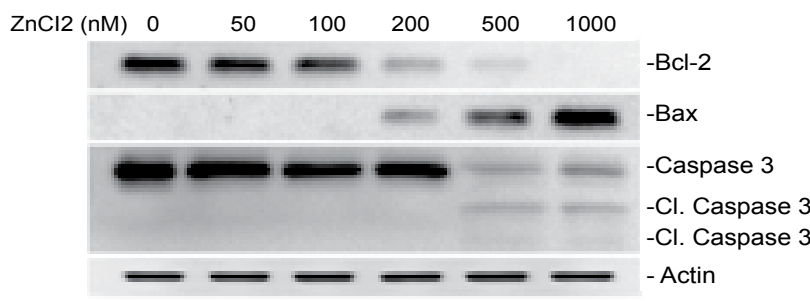

Fig. 4: Zinc chloride enhanced the expression of apoptotic proteins in HFDPCs

Cell lysates from HFDPCs were prepared, and the levels of Bcl-2, Bax, caspase-3, and actin were determined by immunoblotting

Whether the concentrations of zinc used in this study were similar to the concentrations of zinc found in the hair follicles of subjects without hair loss requires further investigation. This study revealed that zinc chloride at concentrations ranging from 100-1000 nM significantly increased HFDPC proliferation. Present results demonstrated that zinc chloride increased the levels of cell cycle-associated proteins, which are essential for cell proliferation. In addition, increased AKT and ERK activities were observed in zinc chloride-treated HFDPCs. However, increased levels of cell cycle regulators as well as the activated AKT and ERK decreased when HFDPCs were treated with a higher dose of zinc chloride $(1 \mu \mathrm{M})$ suggesting that zinc can induce cell proliferation in a narrow dose range.

In contrast, treatment with a higher dose of zinc chloride induced HFDPC death. Both the apoptotic Bax protein and caspase- 3 increased in zinc chloridetreated HFDPCs. Moreover, the cell viability of HFDPCs decreased with higher doses of zinc chloride even though cell proliferation increased with an equivalent concentration of zinc chloride. Numerous clinical observations have noted the inconsistent effects of zinc on patients who were diagnosed with hair loss. In all hair loss patients, a lower concentration of serum zinc was observed in the alopecia areata and telogen effluvium groups ${ }^{[5]}$. This result suggested that disturbances in zinc metabolism might play a key role in hair loss.

It is still not clear whether excess zinc induces hair loss. In addition to regulating hair growth, zinc is important for many physiological processes. Excess levels of zinc in muscles may reduce their strength ${ }^{[10]}$, which is linked to a reduced tolerance to cancer therapies. Additionally, chronic levels of excess zinc pose a relative risk for advanced prostate cancer, suggesting that zinc may play a role in prostate carcinogenesis ${ }^{[1]}$. In contrast, dietary zinc has not been shown to be associated with prostate cancer risk, and the risk of advanced prostate cancer decreased with greater intake of supplemental zinc ${ }^{[12]}$. The available evidence for cancer development caused by zinc is quite inconsistent. Regardless of the benefits or harmful effects of zinc on cancer development, an imbalance of zinc metabolism could lead to defects in the immune system that could facilitate tumor progression.

Some studies have attempted to explain the possible effects of zinc deficiency on hair loss. Although zinc has a low toxicity, the results from the present study suggested that the regulation of HFDPC proliferation and death caused by zinc might be directly involved in hair regrowth.

\section{Acknowledgements:}

The authors thank the Core Laboratory of the Buddhist Tzuchi General Hospital for support.

\section{Conflict of interest:}

Authors declare no conflicts of interest.

\section{Financial support and sponsorship:}

This work was supported by Grant (TCRDTPE-107-45) of the Taipei Tzuchi Hospital through the Buddhist Tzuchi Medical Foundation, Taipei, Taiwan.

\section{REFERENCES}

1. McCall KA, Huang C, Fierke CA. Function and mechanism of zinc metalloenzymes. J Nutr 2000;130:1437S-46S.

2. Hojyo S, Fukada T. Roles of Zinc Signaling in the Immune System. J Immunol Res 2016;2016:6762343.

3. Nishiyama S, Futagoishi-Suginohara $\mathrm{Y}$, Matsukura M, Nakamura T, Higashi A, Shinohara M, et al. Zinc supplementation alters thyroid hormone metabolism in disabled patients with zinc deficiency. J Am Coll Nutr 1994;13:62-7.

4. Prasad AS, Mantzoros CS, Beck FW, Hess JW, Brewer GJ. Zinc status and serum testosterone levels of healthy adults. Nutrition 1996;12:344-8.

5. Kil MS, Kim CW, Kim SS. Analysis of serum zinc and copper concentrations in hair loss. Ann Dermatol 2013;25:405-9.

6. Dhaher SA, Yacoub AA, Jacob AA. Estimation of Zinc and Iron Levels in the Serum and Hair of Women with Androgenetic Alopecia: Case-control Study. Indian J Dermatol 2018;63:369-74.

7. Park H, Kim CW, Kim SS, Park CW. The therapeutic effect and the changed serum zinc level after zinc supplementation in alopecia areata patients who had a low serum zinc level. Ann Dermatol 2009;21:142-6.

8. Aiempanakit K, Jandee S, Chiratikarnwong K, Chuaprapaisilp T, Auepemkiate S. Low plasma zinc levels in androgenetic alopecia. Indian J Dermatol Venereol Leprol 2017;83:741.

9. Piccinini L, Borella P, Bargellini A, Medici CI, Zoboli A. A 
case-control study on selenium, zinc, and copper in plasma and hair of subjects affected by breast and lung cancer. Biol Trace Elem Res 1996;51:23-30.

10. Krotkiewski M, Gudmundsson M, Backstrom P, Mandroukas K. Zinc and muscle strength and endurance. Acta Physiol Scand 1982;116:309-11.
11. Leitzmann MF, Stampfer MJ, Wu K, Colditz GA, Willett WC, Giovannucci EL. Zinc supplement use and risk of prostate cancer. J Natl Cancer Inst 2003;95:1004-7.

12. Gonzalez A, Peters U, Lampe JW, White E. Zinc intake from supplements and diet and prostate cancer. Nutr Cancer 2009;61:206-15. 